\title{
Poor quality roughage based complete feed blocks for ruminants
}

\author{
OP Lohan \\ Department of Animal Feed Technology, CCS, Haryana Agricultural University, Hisar 125004, India
}

\begin{abstract}
Cereal crop residues are the staple feed for livestock in India and other countries of the third world. Every year an average of about 62.4 million tonnes of these residues are transported from surplus to deficit regions in India alone, which costs about 15000/-million rupees annually. The high cost of transportation is mainly due to the low bulk density $\left(65-75 \mathrm{~kg} / \mathrm{m}^{3}\right)$ of these residues. Several workers produced pelleted complete feeds, but pelleting of complete feeds increases the cost due to grinding. Recently in our laboratory, densified complete feed blocks were developed using chaffed/threshed cereal residues and were evaluated in growing buffalo calves and lactating cross bred cattles.
\end{abstract}

Production of complete feed blocks:

For the production of wheat straw based complete feed blocks, the wheat straw was treated with $15 \%$ molasses. Molasses was used as binder. Molasses-treated straw was mixed with concentrate in a ratio of 60:40. The concentrate mixture consisted of barley 45 parts, ground nut cake 33 parts, deoiled rice polish 9 parts, mineral mixture 2 parts and common salt 1 part. The complete feed mixture was pressed into blocks using a hydraulic press. The size of the press jacket was $9 \times 18$ and the weight of each block was $3.5 \mathrm{~kg}$.

Experiment $\mathrm{I}: 12$ buffalo calves of same age were randomly divided into two groups, having 6 animals in each. In group one $\left(T_{1}\right)$ complete feed blocks were offered, while an another group $\left(T_{2}\right)$ was fed mesh form of the feed. The experiment continued for 90 days. The DM intake/100 kg body wt/day was $2.76 \pm 0.04$ and $2.52 \pm 0.03 \mathrm{~kg}$ in $T_{1}$ and $T_{2}$ groups, respectively. The digestibility coefficients for $\mathrm{CP}$, crude fibre, organic matter, DM and NFE were almost similar in both the groups. However, the daily body weight gain was significantly ( $P$ 0.01) higher in $T_{1}$ group (431.52 $\pm 17.11 \mathrm{~g})$ than in $T_{2}$ group $(384.15 \pm 20.26 \mathrm{~g})$.

Experiment II: fifteen lactating cattle were randomly divided into 3 groups (5 cattle in each) in such a way that milk yield in each group was the same. Group one $\left(T_{1}\right)$ was fed complete feed blocks, group two $\left(T_{2}\right)$ was fed complete pelleted feed, and group three $\left(T_{3}\right)$ was fed mesh form of feed ad lib. In addition to these treatments, $10 \mathrm{~kg}$ of green fodder and 1 $\mathrm{kg}$ wheat bran was offered to each animal in each group. The wheat bran was fed at the time of milking in milking parlour to enable milk ejection. The milk yield (I/animal/day) was 7.96 , 7.28 and 7.12 and FCM yield was 8.09, 7.09 and $7.36 \%$ in $T_{1}, T_{2}$ and $T_{3}$ ration-fed groups respectively. However, the differences were non-significant. In $\mathrm{T}_{1}$ group the fat percentage $(4.13 \%)$ was highest, followed by $T_{3}$ group $(4.09 \%)$, and was lowest in $T_{2}$ group (3.83\%). The crude fibre digestibility coefficients were $54.06,50.6$ and $55.23 \%$ in $T_{1}, T_{2}$ and $T_{3}$ groups, being significantly (P 0.01) lower in $T_{2}$ group. DM, CP and NFE digestibility coefficients were not affected by the treatments. DM intake per $100 \mathrm{~kg}$ body weight was also similar in $T_{1}$ (3.32), $T_{2}$ (3.54) and $T_{3}$ (3.21) groups.

The increase in bulk density of the complete feed, as compared to mesh form, was nearly three times (2.79 times) and has no adverse effect on the feed intake and nutrients digestibility. 